Published in final edited form as:

Lancet Diabetes Endocrinol. 2017 January ; 5(1): 53-64. doi:10.1016/S2213-8587(16)30107-3.

\title{
Influence of maternal obesity on the long-term health of offspring
}

\author{
Keith M. Godfrey ${ }^{1,{ }^{*}, \text { Rebecca M. Reynolds }}{ }^{2,{ }^{*}}$, Susan L. Prescott ${ }^{3}$, Moffat Nyirenda $^{4}$, Vincent \\ W.V. Jaddoe ${ }^{5}$, Johan G. Eriksson ${ }^{6}$, and Birit F.P Broekman ${ }^{7}$
}

\begin{abstract}
${ }^{1}$ MRC Lifecourse Epidemiology Unit and NIHR Southampton Biomedical Research Centre, University of Southampton and University Hospital Southampton NHS Foundation Trust 2Endocrinology Unit, University/BHF Centre for Cardiovascular Science, University of Edinburgh, Queen's Medical Research Institute, Edinburgh ${ }^{3}$ School of Paediatrics and Child Health, and Telethon Kids Institute, University of Western Australia ${ }^{4}$ London School of Hygiene and Tropical Medicine, London, UK and College of Medicine, University of Malawi, Blantyre, Malawi ${ }^{5}$ Department of Epidemiology, Department of Pediatrics, Erasmus University Medical Center, Rotterdam, The Netherlands ${ }^{6}$ Department of General Practice and Primary Health Care, University of Helsinki and Helsinki University Hospital, Helsinki, Finland and Folkhälsan Research Center, Helsinki, Finland ${ }^{7}$ Singapore Institute for Clinical Sciences, Agency for Science, Technology and Research (A*STAR), Singapore; Department of Psychological Medicine, Yong Loo Lin School of Medicine, National University of Singapore, and National University Health System, Singapore
\end{abstract}

\section{Abstract}

\begin{abstract}
Alongside its immediate implications for pregnancy complications, increasing evidence implicates maternal obesity as a major determinant of health in the offspring during childhood and later adult life. Observational studies provide evidence for effects of maternal obesity on the offspring's risks of obesity, coronary heart disease, stroke, type 2 diabetes and asthma. Maternal obesity may also lead to poorer cognitive performance in the offspring and an increased risk of neurodevelopmental disorders including cerebral palsy. Preliminary evidence suggests potential implications for immune and infectious disease related outcomes. Insights from experimental studies support causal effects of maternal obesity on offspring outcomes, mediated at least in part through changes in epigenetic processes including alternations in DNA methylation, and perhaps through alterations in the gut microbiome. Although the offspring of obese women who lose weight prior
\end{abstract}

Correspondence to: Professor Keith Godfrey, University of Southampton and MRC Lifecourse Epidemiology Unit, University Hospital Southampton, Tremona Road, Southampton, SO166YD kmg@mrc.soton.ac.uk.

*oint first authors

Conflict of interest statement

KMG reports other from Nestle Nutrition Institute, grants from Abbott Nutrition \& Nestec, outside the submitted work; in addition, KMG has a patent Phenotype prediction pending, a patent Predictive use of $\mathrm{CpG}$ methylation pending, and a patent Maternal Nutrition Composition pending. SLP reports other from Danone Scientific Advisory Board, other from Nestle Nutrition Institute Scientific Advisory Board, other from ALK Abello, outside the submitted work. The other authors have nothing to disclose.

Authors' contributions

All authors each drafted parts of the Series paper, which were subsequently integrated by KMG and RMR. The final version of the manuscript was corrected where needed and approved by all authors. 
to pregnancy have a reduced risk of obesity, to date few controlled intervention studies have reversed maternal obesity and examined the consequences for the offspring. The long term effects of maternal obesity may have profound public health implications and indicate the urgency of studies on causality, underlying mechanisms and effective interventions to reverse the epidemic of obesity in women of child-bearing age and to mitigate its consequences for the offspring.

\section{Introduction}

Maternal obesity is widely recognised for its immediate implications in terms of pregnancy complications, including gestational diabetes, pre-eclampsia and delivery of large-forgestational infants. 1 More recently the recognition that developmental influences can have long term consequences on offspring health and wellbeing has focused attention on the potential for maternal obesity to be one of the influences contributing to the "developmental origins of health and disease". 2 The high prevalence of maternal obesity associated with the global obesity epidemic dictates that determination of any such long-term effects is now an urgent priority. 3

While control for potentially confounding variables remains a challenge in human observational studies, an extensive experimental literature in rodents and non-human primates has demonstrated that maternal obesity induced by dietary intervention leads to obesity, diabetes, raised blood pressure, fatty liver and behaviour changes in the offspring. 4 Maternal obesity has been shown to permanently alter a variety of metabolic control processes in the fetus, including the hypothalamic response to leptin and subsequent regulation of appetite and pancreatic beta cell physiology.4 Mechanisms are likely multifactorial but potentially include maternal metabolic changes such as changes in glucose and fatty acids, 5 altered maternal hypothalamic-pituitary-adrenal axis activity 6 and changes in placental function and inflammation.7

In this Series paper, we review the evidence linking maternal obesity with long-term offspring consequences, focusing on body composition, cardiometabolic, allergic, immune/ infectious and neuro-behavioural outcomes and discuss altered epigenetic processes as a likely major mechanism underlying long-term effects of maternal obesity on the offspring.

\section{Body composition and cardiometabolic outcomes}

An accumulating body of evidence suggests that maternal pre-pregnancy obesity and excessive gestational weight gain are associated with an increased risk of obesity in the offspring during childhood.8-11 While the initial focus was on extreme categories of maternal obesity, several recent studies suggest that higher maternal pre-pregnancy body mass index (BMI) across the full spectrum is associated with greater childhood adiposity and an adverse body fat distribution.12-15 Higher gestational weight gain is also associated with a higher childhood BMI and greater fat mass estimated by dual-energy X-ray absorptiometry.15-20 Whilst both maternal pre-pregnancy obesity and excessive gestational weight gain seem to be associated with a higher blood pressure, adverse lipid profile, and insulin resistance in childhood,12,16,20,21 there is some evidence that these associations are largely mediated by childhood BMI.12,16 
Alongside studies focused on outcomes in children, multiple studies have suggested that a higher maternal pre-pregnancy BMI and greater gestational weight gain are associated with a higher BMI in adolescents and adults.22-29 A study of 2,432 Australians found that greater maternal gestational weight gain was associated with a higher BMI (on average 0.3 $\mathrm{kg} / \mathrm{m}^{2}\left(95 \%\right.$ CI $\left.0.1-0.4 \mathrm{~kg} / \mathrm{m}^{2}\right)$ higher for each $0.1 \mathrm{~kg} /$ week greater gestational weight gain) in the offspring at the age 21 years.29 These associations were independent of maternal prepregnancy BMI. Similarly, a study among 1400 mother-offspring pairs in Jerusalem showed that higher maternal pre-pregnancy BMI was associated with higher offspring BMI at age 30 years (an increase of $1.8 \mathrm{~kg} / \mathrm{m}^{2}$ in offspring BMI per increase of one standard deviation in maternal pre-pregnancy BMI).23 In this study the associations of maternal pre-pregnancy BMI with cardiovascular risk were fully explained by adult BMI.23 Findings from the Helsinki Birth Cohort Study (HBCS) suggest that maternal BMI is positively associated with offspring BMI at age 60 years.30,31 A higher maternal BMI was also associated with a less favourable body fat distribution in female offspring at a mean age of 62 years.31 Similarly to the studies in children, no consistent associations of maternal BMI with other cardiovascular risk factors were present among adults. Inconsistencies may be due to study design and availability of measurements and confounding factors.

Findings from registration/register-based and retrospective cohort studies in Helsinki implicate maternal obesity in pregnancy as an important determinant of the risk of cardiovascular morbidity and mortality in the offspring. A further study using birth records from 37,709 individuals in the UK showed that a higher maternal BMI was associated with an increased risk of premature all-cause mortality (hazard ratio HR 1.35, 95\% CI 1.17-1.55) and hospital admissions for cardiovascular events in adult offspring (HR 1.29, 95\% CI 1.06-1.57).32 These associations were independent of socioeconomic status and current age. In line with these findings, similar findings have been reported in the Helsinki Birth Cohort Study participants born 1934-44 and followed up between the years 1971 to 2010.33 Cardiovascular disease, coronary heart disease, type 2 diabetes and stroke were all more common among offspring of obese mothers. For cardiovascular disease, findings were similar for males and females, while for type 2 diabetes the association was stronger in women. The association of maternal BMI with offspring coronary heart disease was statistically significant among males only (trend per kg/ $\mathrm{m}^{2} \mathrm{HR} 1.031,95 \%$ CI 1.009-1.054), whereas the association of maternal BMI with stroke was significant among females only (trend per $\mathrm{kg} / \mathrm{m}^{2} \mathrm{HR} 1.059,95 \%$ CI 1.019-1.101).33

Several studies have aimed to identify critical periods of maternal weight during pregnancy for childhood outcomes. A study performed among 5,000 UK mother-offspring pairs showed that gestational weight gain in the first 14 weeks of pregnancy was positively associated with offspring adiposity at 9 years of age.17 Likewise a study among 6,000 Dutch mother-offspring dyads showed that early-pregnancy weight gain was associated with an adverse cardio-metabolic profile (OR $1.2095 \%$ CI 1.07- 1.35) in childhood 16 and that this finding was independent of maternal weight gain before pregnancy and of weight gain in later pregnancy. These studies suggest that maternal weight gain in early pregnancy, when maternal fat accumulation forms a relatively large component of gestational weight gain,34 may be a critical period for an adverse childhood cardiovascular risk profile. 
Thus, maternal pre-pregnancy obesity and gestational weight gain, especially in early pregnancy, may influence the risks of adiposity and adverse cardiovascular risk from childhood to adulthood.

\section{Allergic and atopic outcomes}

The global rise in maternal obesity has been implicated in the parallel rising burden of asthma, allergic disease and other early immune diseases, with speculation that this may be part of the multisystem consequences of obesity-related inflammation for the offspring. Indeed, a recent meta-analysis that included 14 studies and 108,321 mother-child pairs found that maternal overweight or obesity in pregnancy were associated with increased risks of childhood asthma or wheeze ever (OR 1.31, 95\%CI 1.16-1.49) and current asthma or wheeze (OR 1.21; 95\%CI, 1.07-1.37), independent of offspring BMI.35 Higher maternal gestational weight gain was also associated with higher offspring odds of current asthma or wheeze (OR 1.015 per $1 \mathrm{~kg}$ increase, 95\% CI 1.01-1.02) but not associated with asthma or wheeze ever (OR $=1.04$ per kg, 95\% CI 0.97-1.11). Follow up of the Danish National Birth Cohort found that the impact of maternal obesity was largely limited to asthma and wheezing, and did not increase the risk of eczema, sensitisation (largely assessed to aeroallergens) or hay fever,36 suggesting tissue specific effects. This is consistent with evidence that allergic diseases result from both systemic immune dysregulation and tissuespecific effects during critical stages of development.

Whilst pathways linking maternal obesity to offspring allergic and atopic outcomes are multifactorial, the contribution of reduced microbial diversity, and in particular intestinal dysbiosis, has emerged as a central risk factor. Changing microbial exposure has been long implicated in the dramatic increase in early-onset inflammatory non-communicable disease such as allergy and asthma, but the importance of these complex microbiological ecosystems is becoming increasingly apparent in the physiological, immunological, and metabolic dysregulation seen in obesity.37 Emerging evidence suggests the multisystem influences of declining microbial diversity also begin in utero, including through epigenetic influences. 38

Thus, an aberrant gut microbiome, known to be associated with maternal obesity, provides an additional mechanism for both the immune and metabolic consequences on the developing fetus. 39 There is preliminary evidence in humans that dietary manipulation of the maternal microbiome in pregnancy with prebiotic fibre has beneficial effects for both offspring immune function and metabolism (reviewed in [40]). In animal models this can prevent the development of an allergic asthma phenotype in the offspring - an effect directly mediated by the short chain fatty acid (SCFA) metabolites produced by microbial fermentation of dietary fibre.41 In addition to their effects on metabolism, glucose homeostasis and appetite regulation, SCFA also have powerful anti-inflammatory effects both in local tissues and systemically through regulatory $\mathrm{T}$ cell induction.40,41 Notably, this includes tissue-specific effects in the lung. Moreover, there is preliminary evidence in humans that high SCFA (acetate) levels in pregnancy correlates with fewer doctor visits for cough and wheeze in their offspring.41 This provides a novel perspective on how a Westernstyle fast food diet associated with obesity might increase asthma risk, whereas a Mediterranean diet (high in fish, fruits, nuts and vegetables) might be protective against 
wheeze and asthma in childhood42; such an effect could be mediated, at least in part, through the microbiome and its metabolic effects on immune responses and tissue function.

Collectively these observations underscore the complex interplay between evolving metabolic and immune responses and how these may be modified by maternal nutrition, adiposity and microbial diversity to alter susceptibility to inflammatory diseases across the lifecourse. 43

\section{Other immune and infectious disease related outcomes}

Whether maternal obesity increases offspring susceptibility to other immune and infectious disease related outcomes has been less well studied, but is important to consider given the rising increases in obesity in low- and middle-income countries 44 where the burden of infection during pregnancy and in childhood is high. With dampened maternal immunity to tolerate the semi-allogenic offspring, pregnancy represents a period of increased susceptibility to infection, and maternal obesity further increases this risk. 45 Studies in rodent models of maternal obesity demonstrate worse offspring outcomes in response to bacterial infection and experimentally induced autoimmunity.46,47

In humans, maternal obesity also impacts the maturation and development of the newborn immune system, with adverse influences on the frequency and function of key innate and adaptive immune cells measured in umbilical cord blood.48 Infants born in developed countries also have different proportions of circulating immune cells and innate immune responses compared to those born in developing countries, but at present little is known about the contributions of maternal nutritional state vs. other exposures (e.g. infections) to these differences. 49 The difference may, however, have important effects on susceptibility to pathogens, responses to vaccines, and development of immunopathological disorders such as asthma and allergy.50 Obesity is a recently recognised risk factor for severe viral infections, 51 and in obese mothers prenatal exposure to a range of infections (such as influenza, Toxoplasma gondii, rubella, cytomegalovirus and herpes simplex virus) could have consequences for the offspring, including cardiometabolic and neurobehavioural diseases. It is not known if maternal obesity further increases susceptibility to vertical transmission of pathogens, though it is plausible that this may occur indirectly through exacerbation of the already altered maternal endocrine, immune, metabolic milieu and inflammatory status associated with maternal adiposity.52,53

A further important consideration is whether therapies used to treat maternal infection can also have adverse impacts on the offspring's risk of later disease, through increasing maternal adiposity. Notably protease inhibitors, antiretrovirals (ARVs) used to prevent mother-to-child transmission of HIV, are associated with adverse maternal metabolic side effects. These include changes in maternal body composition including increased central adiposity, together with associated dyslipidaemia, insulin resistance, type 2 diabetes and mitochondrial toxicity which may have long term effects on ARV-exposed infants.54 Detailed studies will be required to establish the long term effects, and to determine optimal regimens to reduce any adverse outcomes. 


\section{Offspring neurocognitive and behavioural outcomes}

Despite the potential public health importance, relatively few cohort studies have examined associations between maternal obesity and detailed neuro-developmental outcomes in offspring (Table 1). For cognitive outcomes, human data showed that higher pre-pregnancy weight is associated with poorer cognitive outcomes, while higher (but not excessive) weight gain during pregnancy has been associated with better offspring cognitive outcomes.55,56 However, published data do not allow definitive conclusions of potential effects of prepregnancy adiposity on offspring cognitive development. Most studies found modest inverse associations with both early and later cognitive standardized assessments or reading and math scores, 57 while a recent study found indications for a possible temporary increase in cognitive outcomes on a standardized assessment at 6 months. 58 However, associations with maternal reports of cognitive performance were inconsistent in other large cohort studies.59

Maternal obesity has also been associated with offspring behavioural and emotional problems.57,60 A recent meta-analysis and longitudinal study found an increased risk for Autism Spectrum Disorders in children of mothers with obesity before/during pregnancy or excessive gestational weight gain,60,61 with other approaches suggesting a particularly robust association for excessive gestational weight gain .62 In 3 large European cohort studies the association between pre-pregnant obesity and Attention Deficit Hyperactivity Disorder was inconsistent, and lost when adjusted in full sibling comparisons.59,63 Fewer studies have investigated the association with affective disorders and no recent studies have investigated the link with anxiety, psychotic or eating disorders. Only one qualitative review has been published on pre-pregnancy obesity and schizophrenia, which suggested an association, although maternal schizophrenia was not taken into account.64 Although past studies reported contradictory results relating maternal obesity to offspring cerebral palsy,65 large studies over the last 5 years have found positive associations, even after multiple adjustments. 57

One major limitation of the above-mentioned studies is the difficulty in differentiating intrauterine effects from residual confounding. One way to explore this is to compare effect sizes of maternal obesity versus paternal obesity. However, even with maternal effect sizes, it is clear that other influences are also associated with both obesity and neurodevelopment, such as maternal intelligence, socio-economic status, breastfeeding, maternal mental health, maternal diet and other postnatal lifestyle influences. Other reasons for contradictory findings are differences in methodology, sampling biases, different ages of measuring outcomes and differences in defining obesity and outcomes. Some studies used retrospective self-reports of pre-pregnancy weight or maternal reports of offspring outcomes, which may be less reliable.55,59

In human studies it is difficult to confirm causation or to identify mechanisms linking maternal obesity with offspring neurodevelopment. However, studies in rodents and nonhuman primates have indicated 3 potential pathways: 1) high levels of nutrients, including fatty acids and glucose; 2) high levels of hormones like leptin and insulin; 3) inflammatory mediators, including interleukins and tumor necrosis factor.57,66 These factors cross the placenta and can influence fetal neuroendocrine development, neuronal proliferation and 
brain development.57,66 Many dynamic factors play a role, with complex interactions between maternal environment, placental patho-physiology and fetal epigenetic changes. Indeed, animal studies showed that obesity during pregnancy can change brain homeostasis and offspring behaviour through epigenetic mechanisms, including in the serotonin and dopamine pathways, lipid peroxidation and corticosteroid receptor expression.67,68 Even parental lifestyle factors prior to and at conception may have transgenerational effects by epigenetic reprogramming at fertilization.69

Maternal obesity has many pathophysiological features in common with gestational diabetes, a condition increasingly associated with evidence of mild cognitive impairment in the offspring.58 For maternal obesity the paucity of current evidence indicates a need for large-scale studies with more detailed cognitive and behavioural phenotyping in populations of different cultures and ethnicities. Future studies should examine if maternal diet or obesity itself is more important for programming of neurodevelopmental outcomes, and include comprehensive assessments of diet and direct measurements of adiposity. Moreover, underlying mechanisms should be studied in humans with biomarkers including genetic and epigenetic modifications.

\section{Epigenetic modifications: a potential underlying mechanism}

Epigenetic processes are emerging as an important mechanism through which the "memory" of developmental exposures is held, with pathophysiological consequences for a variety of organs and systems. Epigenetic modifications have been proposed as a key causal mechanism linking maternal adiposity and offspring outcome.70 Moreover, there is now emerging evidence that epigenetic processes can act over several generations, including three or more generations and through the paternal line.71 Epigenetic modifications result in alterations in gene function in the absence of changes in the DNA sequence. The epigenetic marks which mediate this include DNA methylation, post-translational modification of histones and non-coding RNAs. DNA methylation occurring predominantly at cytosines in cytosine-guanine $(\mathrm{CpG})$ dinucleotides is the most widely studied. Table 2 summarises the existing evidence linking maternal obesity in humans with offspring DNA methylation.

As shown in Table 2, a number of studies have used global methylation techniques to explore associations between maternal obesity and offspring DNA methylation. Though the findings are not consistent, three cohort studies found associations between maternal BMI and offspring DNA methylation at birth72,73 and at 3 years. 74 Notably, in the largest and methodologically most robust study 73 the methylation differences were only observed with comparisons of extreme groups of BMI (i.e. obese vs normal-weight) and not when the overweight group was compared with normal-weight group. Reasons are unknown but this observation may partly explain the negative findings in other studies where analyses have been conducted across a range of maternal BMI measurements.75,76 The observation of differentially methylated $\mathrm{CpG}$ sites in the peripheral blood of 2-25 year old siblings born to obese mothers before and after bariatric surgery with associated weight loss77 is also consistent with the hypothesis that maternal obesity impacts on offspring DNA methylation. 
Where a candidate gene approach has been adopted, associations between maternal adiposity and DNA methylation at imprinted genes $78-80$ or in a number of genes known to be involved in metabolism78-82 have been reported. Of particular interest is the observation that aryl-hydrocarbon receptor repressor (AHRR) DNA methylation is $2.1 \%$ higher in offspring of obese vs. normal weight mothers81; robust links are now established between maternal smoking and offspring AHRR methylation and there is much evidence that maternal smoking is associated with long term effects on offspring adiposity. 15 The observations raise the possibility that AHRR DNA methylation may be involved in the link between maternal obesity and offspring adiposity. There is also evidence that maternal glycaemia is involved in causal pathways influencing offspring leptin epigenetic regulation. 83

\section{Methodological considerations}

Fixed genetic variants shared by mother and offspring are important confounders of proposed links between metabolic factors linked to maternal obesity and offspring outcomes, as are shared postnatal influences on diet/lifestyle behaviours 84 and microbiome-related mechanisms. 85 However, abdominal fat depots already differ at birth between groups with different risks of later metabolic disease 86 and it seems likely that at least some of the effects of maternal obesity are mediated through prenatal environmental mechanisms. Further delineation of maternal effect modifiers will aid the development of interventions to improve offspring health, as will understanding of the underlying mechanisms and related biomarker signatures of these processes. Alongside giving insights into the fundamental processes and additional risk factors, such signatures will provide immediate outcome/ adherence measures for interventions, and enable identification of postnatal effect modifiers and stratification of infants for targeting of postnatal interventions.

Whilst the available data is consistent with the hypothesis that maternal obesity impacts on offspring DNA methylation changes at birth, whether these changes impact on development of later adverse outcomes in the offspring remains unclear. The observation that the methylation changes found at birth were also present at 3 year follow-up, 74 provides some evidence that the methylation changes may persist over time. This, together with the observation of persistence of epigenetic marks associated with obesity across childhood and adolescence, 87 raises the possibility that epigenetic analysis may provide useful biomarkers of disease risk across the lifespan. The findings do need to be interpreted with caution. Few studies have included attempts to replicate or validate findings through using a replication cohort,76 validation in comparison with published data73 or sex specificity. It is well established that many DNA methylation patterns are tissue- and cell- specific, 88 so the relevance of findings from DNA extracted from cord or peripheral blood leukocytes remains unclear. However, there is also evidence that, for a number of non-imprinted genes, DNA methylation levels measured in blood are equivalent in buccal cells despite the fact that these cell types arise from different germ layers (mesoderm and ectoderm respectively). 89

Whilst the majority of studies have utilised DNA extracted from blood leukocytes as a window on processes occurring in the fetus,72-76,78-81 the heterogeneity in sample population, study size, and the inconsistency between methodological approaches, makes 
comparison of studies challenging. Further, methodological considerations, particularly if complex tissues are used such as the placenta which contains mixed cell types, each with a distinct methylation pattern, may present problems with data interpretation.

We do not know whether the reported associations between maternal obesity and epigenetic processes are causal in relation to later outcomes, or whether they are merely a response to the maternal obesogenic environment, or are secondary to the changes in growth that occur in a fetus exposed to maternal obesity in utero. Obesity is also associated with changes in intestinal microbiota and epigenetic changes can also be induced by gut microbiome metabolites such as short chain fatty acids. Obesity associated changes in intestinal microbiota have implications for infant microbiome development with consequences for later child outcomes.90 Postnatal colonization of the microbiome in offspring has been linked to changes of the hypothalamic-pituitary-adrenal axis linking brain function and intestinal bacteria.91 Studies indeed showed associations between changes in the microbiome and neurodevelopment disorders in which inflammation is implicated, such as autism-spectrum disorders and attention-deficit hypersensitivity disorder.92

Studies to test causality for effects of maternal obesity on offspring epigenetics in humans are hard to conduct; however, utilising associations with paternal obesity as a "negative control', the demonstration that epigenetic modifications are more strongly associated with maternal than paternal obesity 73 provides some support for the thesis that the associations of maternal obesity with offspring methylation are due to an intrauterine mechanism. The experimental demonstration that paternal diet prior to conception can have lasting effects on offspring outcomes through epigenetic processes does, however, add further complexity to an already complex situation.69 Further, many of the techniques used to investigate global DNA methylation changes are limited in coverage of the human epigenome. For example, the Infinium HumanMethylation450 BeadChip array used in many recent studies 73,77 only covers around $1.7 \%$ of all $\mathrm{CpG}$ sites in the genome and to date there has been little consideration of non-CpG methylation or 5-hydroxymethylation.93 More studies are needed that consider interaction of epigenetic changes with changes in the genome - recent studies suggest that around a quarter of the variation in neonatal methylomes arises from fixed genetic variants, with the remainder from gene-environment interactions.94

\section{Conclusion}

Although initial research linking developmental influences with major non-communicable disorders in later life focused on the effects of fetal undernutrition, increasing evidence indicates that exposure to maternal obesity also leads to an increased risk of disease in the offspring. Observational studies have provided strong evidence for associations between maternal obesity and an increase in the offspring's risk of obesity, coronary heart disease, stroke, type 2 diabetes and asthma. Emerging evidence suggests that maternal obesity may be associated with poorer cognition in the offspring and an increased risk of neurodevelopmental disorders including cerebral palsy. With the exception of recent small studies of obese women who had bariatric surgery between pregnancies, there is a paucity of controlled intervention studies that have reversed maternal obesity and examined the consequences for the offspring. However, the offspring of obese women who lose weight 
prior to pregnancy have reduced risk of obesity 95 , and insights from experimental studies support a causal effect of maternal obesity on offspring outcomes in later life. Mechanistic insights also support causal effects on maternal obesity on the offspring, mediated through changes in epigenetic processes, and perhaps through alterations in the gut microbiome of the offspring. Table 4 lists key points for further research.

Greater insight is needed into the mechanisms acting in the mother, through which maternal obesity and excess nutrient supply impart increased risk for future metabolic disease. Prepregnancy obesity predisposes the mother to gestational diabetes, hypertension and preeclampsia which may affect placental function and fetal energy metabolism. In addition, obesity in pregnancy is associated with complex neuroendocrine, metabolic and immune/ inflammatory changes which likely impact on fetal hormonal exposure and nutrient supply. 6,96

The observations linking maternal obesity with lifelong consequences for the offspring have profound public health implications. The prevalence of overweight/obesity in women of childbearing age is increasing worldwide (with over $60 \%$ of women either overweight or obese at conception in the United States97), which will increase population of children exposed to an "obese intrauterine environment" and thus perpetuate cycle of increasing obesity and chronic disease burden. Public health measures that will rapidly reverse the current epidemic of maternal obesity appear implausible at present; in their absence, breaking the cycle of maternal and offspring obesity requires from a new generation of intervention studies, based on more detailed analysis of observational studies and designed with a better understanding of the underpinning mechanisms acting in the mother and offspring.

\section{Search strategy}

In this section we systematically reviewed studies with MEDLINE (1980-2015, EMBASE (1980-2015) and Cochrane library (1980-2015) with the search terms "maternal obesity", "pre-conception", "pregnancy", "intergenerational", "offspring" or "infant" or "child" in combination with the terms "fetal programming", "epigenetic", "methylation", "disease", "immunity", "cardiovascular", "type 2 diabetes", "infection", "HIV", "malaria", "proinflammatory", "cognition", "school performance", "psychopathology", "mental health", "ADHD", "autism", "affective disorders", "anxiety disorders", "eating disorders", "psychotic disorders" and "cerebral palsy". We selected large cohort and case-control studies that were judged relevant, with a focus on studies conducted over the last 10 years in humans, but not excluding commonly referenced and highly regarded older publications. We also included references of articles identified by our search strategy and included those that were found relevant.

\section{Acknowledgements}

KMG is supported by the National Institute for Health Research through the NIHR Southampton Biomedical Research Centre and by the European Union's Seventh Framework Programme (FP7/2007-2013), projects EarlyNutrition and ODIN under grant agreement numbers 289346 and 613977. VWVJ received an additional grant from the Netherlands Organization for Health Research and Development (NWO, ZonMw-VIDI 016.136.361) and an European Research Council Consolidator Grant (ERC-2014-CoG-648916). JGE was supported by EU FP7 
(DORIAN) project number 278603 and EU H2020-PHC-2014-DynaHealth, Grant no. 633595. RMR acknowledges support from Tommy's and the British Heart Foundation. The funding sources had no influence on the content of this review.

\section{References}

1. Norman JE, Reynolds RM. The consequences of obesity and excess weight gain in pregnancy. Proc Nutr Soc. 2011; 70:450-6. [PubMed: 21880162]

2. Drake AJ, Reynolds RM. Impact of maternal obesity on offspring obesity and cardiometabolic disease risk. Reproduction. 2010; 140:387-398. [PubMed: 20562299]

3. Heslehurst N, Rankin J, Wilkinson J, Summerbell C. A nationally representative study of maternal obesity in England, UK: trends in incidence and demographic inequalities in 619,323 births, 19892007. Int J Obes (Lond). 2010; 34:420-428. [PubMed: 20029373]

4. Patel N, Pasupathy D, Poston L. Determining the consequences of maternal obesity on offspring health. Exp Physiol. 2015; 100:1421-8. [PubMed: 26464224]

5. Nelson SM, Matthews P, Poston L. Maternal metabolism and obesity: modifiable determinants of pregnancy outcome. Hum Reprod Update. 2010; 16:255-75. [PubMed: 19966268]

6. Stirrat LI, O'Reilly JR, Barr SM, et al. Decreased maternal hypothalamic-pituitary-adrenal axis activity in very severely obese pregnancy: Associations with birthweight and gestation at delivery. Psychoneuroendocrinology. 2016; 63:135-43. [PubMed: 26444587]

7. Lewis RM, Demmelmair H, Gaillard R, Godfrey KM, Hauguel-de Mouzon S, Huppertz B, Larque E, Saffery R, Symonds ME, Desoye G. The placental exposome: placental determinants of fetal adiposity and postnatal body composition. Ann Nutr Metab. 2013; 63:208-15. [PubMed: 24107818]

8. Gaillard R, Felix JF, Duijts L, Jaddoe VW. Childhood consequences of maternal obesity and excessive weight gain during pregnancy. Acta Obstet Gynecol Scand. 2014; 93:1085-9. [PubMed: 25231923]

9. Gaillard R. Maternal obesity during pregnancy and cardiovascular development and disease in the offspring. Eur J Epidemiol. 2015; 30:1141-52. [PubMed: 26377700]

10. Yu Z, Han S, Zhu J, Sun X, Ji C, Guo X. Pre-pregnancy body mass index in relation to infant birth weight and offspring overweight/obesity: a systematic review and meta-analysis. PLoS ONE. 2013; 8:e61627. [PubMed: 23613888]

11. Tie HT, Xia YY, Zeng YS, et al. Risk of childhood overweight or obesity associated with excessive weight gain during pregnancy: a meta-analysis. Arch Gynecol Obstet. 2014; 289:247-57. [PubMed: 24141389]

12. Gaillard R, Steegers EA, Duijts L, et al. Childhood cardiometabolic outcomes of maternal obesity during pregnancy: the Generation R Study. Hypertension. 2014; 63:683-91. [PubMed: 24379180]

13. Catalano PM, Farrell K, Thomas A, et al. Perinatal risk factors for childhood obesity and metabolic dysregulation. Am J Clin Nutr. 2009; 90:1303-13. [PubMed: 19759171]

14. Lawlor DA, Timpson NJ, Harbord RM, et al. Exploring the developmental overnutrition hypothesis using parental-offspring associations and FTO as an instrumental variable. PLoS Med. 2008; 5:e33. [PubMed: 18336062]

15. Robinson SM, Crozier SR, Harvey NC, et al. Modifiable early-life risk factors for childhood adiposity and overweight: an analysis of their combined impact and potential for prevention. Am $\mathrm{J}$ Clin Nutr. 2015; 101:368-75. [PubMed: 25646335]

16. Gaillard R, Steegers EA, Franco OH, Hofman A, Jaddoe VW. Maternal weight gain in different periods of pregnancy and childhood cardio-metabolic outcomes. The Generation R Study. Int J Obes. 2015; 39:677-85.

17. Fraser A, Tilling K, Macdonald-Wallis C, et al. Association of maternal weight gain in pregnancy with offspring obesity and metabolic and vascular traits in childhood. Circulation. 2010; 121:2557-64. [PubMed: 20516377]

18. Crozier SR, Inskip HM, Godfrey KM, et al. Weight gain in pregnancy and childhood body composition: findings from the Southampton Women's Survey. Am J Clin Nutr. 2010; 91:174551. [PubMed: 20375187] 
19. Oken E, Rifas-Shiman SL, Field AE, Frazier AL, Gillman MW. Maternal gestational weight gain and offspring weight in adolescence. Obstet Gynecol. 2008; 112:999-1006. [PubMed: 18978098]

20. Perng W, Gillman MW, Mantzoros CS, Oken E. A prospective study of maternal prenatal weight and offspring cardiometabolic health in midchildhood. Ann Epidemiol. 2014; 24:793-800 e1. [PubMed: 25263237]

21. Oostvogels AJ, Stronks K, Roseboom TJ, van der Post JA, van Eijsden M, Vrijkotte TG. Maternal prepregnancy BMI, offspring's early postnatal growth, and metabolic profile at age 5-6 years: the ABCD Study. J Clin Endocrinol Metab. 2014; 99:3845-54. [PubMed: 24955609]

22. Laitinen J, Jaaskelainen A, Hartikainen AL, et al. Maternal weight gain during the first half of pregnancy and offspring obesity at 16 years: a prospective cohort study. BJOG. 2012; 119:716-23. [PubMed: 22489762]

23. Hochner H, Friedlander Y, Calderon-Margalit R, et al. Associations of maternal prepregnancy body mass index and gestational weight gain with adult offspring cardiometabolic risk factors: the Jerusalem Perinatal Family Follow-up Study. Circulation. 2012; 125:1381-9. [PubMed: 22344037]

24. Tequeanes AL, Gigante DP, Assuncao MC, Chica DA, Horta BL. Maternal anthropometry is associated with the body mass index and waist:height ratio of offspring at 23 years of age. J Nutr. 2009; 139:750-4. [PubMed: 19211832]

25. Reynolds RM, Osmond C, Phillips DIW, Godfrey KM. Maternal BMI, parity and pregnancy weight gain: influences on offspring adiposity in young adulthood. J Clin Endocrinol Metab. 2010; 95:5365-5369. [PubMed: 20702520]

26. Schack-Nielsen L, Michaelsen KF, Gamborg M, Mortensen EL, Sorensen TI. Gestational weight gain in relation to offspring body mass index and obesity from infancy through adulthood. Int $\mathrm{J}$ Obes. 2010; 34:67-74.

27. Hrolfsdottir L, Rytter D, Olsen SF, et al. Gestational weight gain in normal weight women and offspring cardio-metabolic risk factors at 20 years of age. Int J Obes. 2015; 39:671-6.

28. Rooney BL, Mathiason MA, Schauberger CW. Predictors of obesity in childhood, adolescence, and adulthood in a birth cohort. Matern Child Health J. 2011; 15:1166-75. [PubMed: 20927643]

29. Mamun AA, O'Callaghan M, Callaway L, Williams G, Najman J, Lawlor DA. Associations of gestational weight gain with offspring body mass index and blood pressure at 21 years of age: evidence from a birth cohort study. Circulation. 2009; 119:1720-7. [PubMed: 19307476]

30. Forsén T, Eriksson JG, Tuomilehto J, Teramo K, Osmond C, Barker DJ. Mother's weight in pregnancy and coronary heart disease in a cohort of Finnish men: follow up study. BMJ. 1997; 315:837-40. [PubMed: 9353502]

31. Eriksson JG, Sandboge S, Salonen M, Kajantie E, Osmond C. Maternal weight in pregnancy and offspring body composition in late adulthood: findings from the Helsinki Birth Cohort Study (HBCS). Ann Med. 2015; 47:94-9. [PubMed: 25797690]

32. Reynolds RM, Allan KM, Raja EA, et al. Maternal obesity during pregnancy and premature mortality from cardiovascular event in adult offspring: follow-up of 1323275 person years. BMJ. 2013; 347:f4539. [PubMed: 23943697]

33. Eriksson JG, Sandboge S, Salonen MK, Kajantie E, Osmond C. Long-term consequences of maternal overweight in pregnancy on offspring later health: findings from the Helsinki Birth Cohort Study. Ann Med. 2014; 46:434-8. [PubMed: 24910160]

34. Clapp JF 3rd, Seaward BL, Sleamaker RH, Hiser J. Maternal physiologic adaptations to early human pregnancy. Am J Obstet Gynecol. 1988; 159:1456-60. [PubMed: 3207124]

35. Forno E, Young OM, Kumar R, Simhan H, Celedon JC. Maternal obesity in pregnancy, gestational weight gain, and risk of childhood asthma. Pediatrics. 2014; 134:e535-46. [PubMed: 25049351]

36. Harpsoe MC, Basit S, Bager P, Wohlfahrt J, Benn CS, Nohr EA, et al. Maternal obesity, gestational weight gain, and risk of asthma and atopic disease in offspring: a study within the Danish National Birth Cohort. J Allergy Clin Immunol. 2013; 131:1033-40. [PubMed: 23122630]

37. West CE, Renz H, Jenmalm MC, et al. The gut microbiota and inflammatory noncommunicable diseases: associations and potentials for gut microbiota therapies. J Allergy Clin Immunol. 2015; 135:3-13. quiz 4. [PubMed: 25567038]

38. Martino D, Prescott SL. Epigenetics and prenatal influences on asthma and allergic airways disease. Chest. 2011; 139:640-7. [PubMed: 21362650] 
39. Gohir W, Ratcliffe EM, Sloboda DM. Of the bugs that shape us: maternal obesity, the gut microbiome, and long-term disease risk. Pediatr Res. 2015; 77:196-204. [PubMed: 25314580]

40. Thorburn AN, Macia L, Mackay CR. Diet, metabolites, and "western-lifestyle" inflammatory diseases. Immunity. 2014; 40:833-42. [PubMed: 24950203]

41. Thorburn AN, McKenzie CI, Shen S, Stanley D, Macia L, Mason LJ, et al. Evidence that asthma is a developmental origin disease influenced by maternal diet and bacterial metabolites. Nat Commun. 2015; 6:7320. [PubMed: 26102221]

42. Netting MJ, Middleton PF, Makrides M. Does maternal diet during pregnancy and lactation affect outcomes in offspring? A systematic review of food-based approaches. Nutrition. 2014; 30:122541. [PubMed: 25280403]

43. Prescott SL. Early-life environmental determinants of allergic diseases and the wider pandemic of inflammatory noncommunicable diseases. J Allergy Clin Immunol. 2013; 131:23-30. [PubMed: 23265694]

44. Seidell JC, Halberstadt J. The global burden of obesity and the challenges of prevention. Ann Nutr Metab. 2015; 66(S2):7-12.

45. Acosta CD, Knight M. Sepsis and maternal mortality. Curr Opin Obstet Gynecol. 2013; 2:109-16.

46. Odaka Y, Nakano M, Tanaka T, et al. The influence of a high-fat dietary environment in the fetal period on postnatal metabolic and immune function. Obesity. 2010; 18:1688-94. [PubMed: 20111014]

47. Myles IA, Fontecilla NM, Janelsins BM, Vithayathil PJ, Serge JA, Datta SK. Parental dietary fat intake alters offspring microbiome and immunity. J Immunol. 2013; 191:3200-9. [PubMed: 23935191]

48. Wilson RM, Marshall NE, Jeske DR, Purnell JQ, Thornburg K, Messaoudi I. Maternal obesity alters immune cells frequencies and responses in umbilical cord blood samples. Pediatric Allergy Immunol. 2015; 26:344-351.

49. Lisciandro JG, van den Biggelaar AH. Neonatal immune function and inflammatory illnesses in later life: lessons to be learnt from the developing world? Clin Exp Allergy. 2010; 40:1719-31. [PubMed: 20964742]

50. Thornton CA, Macfarlane TV, Holt PG. The hygiene hypothesis revisited: role of materno-fetal interactions. Curr Allergy Asthma Rep. 2010; 10:444-52. [PubMed: 20809222]

51. Almond MH, Edwards MR, Barclay WS, Johnston SL. Obesity and susceptibility to severe outcomes following respiratory viral infection. Thorax. 2013; 68:684-6. [PubMed: 23436045]

52. Nguyen MU, Wallace MJ, Pepe S, Menheniott TR, Moss TJ, Burgner D4. Perinatal inflammation: a common factor in the early origins of cardiovascular disease? Clin Sci (Lond). 2015; 129:76984. [PubMed: 26223841]

53. Simane AM, Meier HC. Association Between Prenatal Exposure to Maternal Infection and Offspring Mood Disorders: A Review of the Literature. Curr Probl Pediatr Adolesc Health Care. 2015; 45:325-64. [PubMed: 26476880]

54. Jao J, Abrams EJ. Metabolic complications of in utero maternal HIV and antiretroviral exposure in HIV-exposed infants. Pediatr Infect Dis J. 2014; 33:734-40. [PubMed: 24378947]

55. Basatemur E, Gardiner J, Williams C, Melhuish E, Barnes J, Sutcliffe A. Maternal prepregnancy BMI and child cognition: a longitudinal cohort study. Pediatrics. 2013; 131:56-63. [PubMed: 23230067]

56. Gage SH, Lawlor DA, Tilling K, Fraser A. Associations of maternal weight gain in pregnancy with offspring cognition in childhood and adolescence: findings from the Avon Longitudinal Study of Parents and Children. Am J Epidemiol. 2013; 177:402-410. [PubMed: 23388581]

57. Mehta SH, Kerver JM, Sokol RJ, Keating DP, Paneth N. The association between maternal obesity and neurodevelopmental outcomes of offspring. J Pediat. 2014; 165:891-896. [PubMed: 25155965]

58. Torres-Espinola FJ, Berglund SK, et al. Maternal Obesity, Overweight and Gestational Diabetes Affect the Offspring Neurodevelopment at 6 and 18 Months of Age--A Follow Up from the PREOBE Cohort. PloS one. 2015; 10:e0133010. [PubMed: 26208217]

59. Brion MJ, Zeegers M, Jaddoe V, et al. Intrauterine effects of maternal prepregnancy overweight on child cognition and behavior in 2 cohorts. Pediatrics. 2011; 127:e202-211. [PubMed: 21187310] 
60. Jo H, Schieve LA, Sharma AJ, Hinkle SN, Li R, Lind JN. Maternal prepregnancy body mass index and child psychosocial development at 6 years of age. Pediatrics. 2015; 135:e1198-1209. [PubMed: 25917989]

61. Li YM, Ou JJ, Liu L, Zhang D, Zhao JP, Tang SY. Association Between Maternal Obesity and Autism Spectrum Disorder in Offspring: A Meta-analysis. J Autism Devel Disorders. 2016; 46:95102.

62. Gardner RM, Lee BK, Magnusson C, et al. Maternal body mass index during early pregnancy, gestational weight gain, and risk of autism spectrum disorders: Results from a Swedish total population and discordant sibling study. Int J Epidemiol. 2015; 44:870-883. [PubMed: 26045508]

63. Chen Q, Sjolander A, Langstrom N, et al. Maternal pre-pregnancy body mass index and offspring attention deficit hyperactivity disorder: a population-based cohort study using a siblingcomparison design. Int J Epidemiol. 2014; 43:83-90. [PubMed: 24058000]

64. Khandaker GM, Dibben CR, Jones PB. Does maternal body mass index during pregnancy influence risk of schizophrenia in the adult offspring? Obesity Rev. 2012; 13:518-527.

65. Crisham Janik MD, Newman TB, Cheng YW, Xing G, Gilbert WM, Wu YW. Maternal diagnosis of obesity and risk of cerebral palsy in the child. J Pediatr. 2013; 163:1307-1312. [PubMed: 23932316]

66. Rivera HM, Christiansen KJ, Sullivan EL. The role of maternal obesity in the risk of neuropsychiatric disorders. Front Neurosci. 2015; 9:194. [PubMed: 26150767]

67. Sullivan EL, Nousen EK, Chamlou KA. Maternal high fat diet consumption during the perinatal period programs offspring behavior. Physiol Behav. 2014; 123:236-42. [PubMed: 23085399]

68. Kang SS, Kurti A, Fair DA, Fryer JD. Dietary intervention rescues maternal obesity induced behavior deficits and neuroinflammation in offspring. J Neuroinflammation. 2014; 11:156. [PubMed: 25212412]

69. Lane M, Zander-Fox DL, Robker RL, McPherson NO. Peri-conception parental obesity, reproductive health, and transgenerational impacts. Trends Endocrinol Metab. 2015; 26:84-90. [PubMed: 25523615]

70. Godfrey KM, Costello PM, Lillycrop KA. The developmental environment, epigenetic biomarkers and long-term health. J Dev Orig Health Dis. 2015; 6:399-406. [PubMed: 26017068]

71. McPherson NO, Owens JA, Fullston T, Lane M. Preconception diet or exercise intervention in obese fathers normalizes sperm microRNA profile and metabolic syndrome in female offspring. Am J Physiol Endocrinol Metab. 2015; 308:E805-21. [PubMed: 25690453]

72. Liu X, Chen Q, Tsai H-J, et al. Maternal preconception body mass index and offspring cord blood DNA methylation: exploration of early life origins of disease. Environ Mol Mutagen. 2014; 55:223-30. [PubMed: 24243566]

73. Sharp GC, Lawlor DA, Richmond RC, et al. Maternal pre-pregnancy BMI and gestational weight gain, offspring DNA methylation and later offspring adiposity: findings from the Avon Longitudinal Study of Parents and Children. Int J Epidemiol. 2015; 44:1288-304. [PubMed: 25855720]

74. Herbstman JB, Wang S, Perera FP, et al. Predictors and consequences of global DNA methylation in cord blood and at three years. PloS One. 2013; 8:e72824. [PubMed: 24023780]

75. Michels KB, Harris HR, Barault L. Birthweight, maternal weight trajectories and global DNA methylation of LINE-1 repetitive elements. PloS One. 2011; 6:e25254. [PubMed: 21980406]

76. Morales E, Groom A, Lawlor DA, Relton CL. DNA methylation signatures in cord blood associated with maternal gestational weight gain: results from the ALSPAC cohort. BMC Res Notes. 2014; 7:278. [PubMed: 24886386]

77. Guénard F, Tchernof A, Deshaies Y, et al. Methylation and expression of immune and inflammatory genes in the offspring of bariatric bypass surgery patients. J Obes. 2013; 2013:492170. [PubMed: 23840945]

78. Hoyo C, Fortner K, Murtha AP, et al. Association of cord blood methylation fractions at imprinted insulin-like growth factor 2 (IGF2), plasma IGF2, and birth weight. Cancer Causes and Control. 2012; 23:635-645. [PubMed: 22392079] 
79. Soubry A, Schildkraut JM, Murtha A, et al. Paternal obesity is associated with IGF2 hypomethylation in newborns: results from a Newborn Epigenetics Study (NEST) cohort. BMC Med. 2013; 6(11):29.

80. Soubry A, Murphy SK, Wang F, et al. Newborns of obese parents have altered DNA methylation patterns at imprinted genes. Int J Obes (Lond). 2015; 39:650-7. [PubMed: 24158121]

81. Burris HH, Baccarelli AA, Byun HM, et al. Offspring DNA methylation of the aryl-hydrocarbon receptor repressor gene is associated with maternal BMI, gestational age, and birth weight. Epigenetics. 2015; 10:913-21. [PubMed: 26252179]

82. Gemma C, Sookoian S, Alvariñas J, et al. Maternal pregestational BMI is associated with methylation of the PPARGC1A promoter in newborns. Obesity (Silver Spring). 2009; 17:1032-39. [PubMed: 19148128]

83. Allard C, Desgagné V, Patenaude J, et al. Mendelian randomization supports causality between maternal hyperglycemia and epigenetic regulation of leptin gene in newborns. Epigenetics. 2015; 10:342-51. [PubMed: 25800063]

84. Fisk CM, Crozier SR, Inskip HM, Godfrey KM, Cooper C, Robinson SM, Southampton Women's Survey Study Group. Influences on the quality of young children's diets: the importance of maternal food choices. Br J Nutr. 2011; 105:287-96. [PubMed: 20807465]

85. Dogra S, Sakwinska O, Soh S-E, et al. Rate of establishing the gut microbiota in infancy has consequences for future health. Gut Microbes. 2015; 6:321-5. [PubMed: 26516657]

86. Tint MT, Fortier MV, Godfrey KM, et al. Abdominal adipose tissue compartments vary with ethnicity in Asian neonates: Growing Up in Singapore Toward Healthy Outcomes birth cohort study. Am J Clin Nutr. 2016 epub Apr 6.

87. Clarke-Harris R, Wilkin TJ, Hosking J, et al. PGC1a promoter methylation in blood at 5-7 years predicts adiposity from 9 to 14 years (EarlyBird 50). Diabetes. 2014; 63:2528-37. [PubMed: 24622795]

88. De Bustos C, Ramos E, Young JM, et al. Tissue-specific variation in DNA methylation levels along human chromosome 1. Epigenetics \& Chromatin. 2009; 2:7. [PubMed: 19505295]

89. Talens RP, Boomsma DI, Tobi EW, et al. Variation, patterns, and temporal stability of DNA methylation: considerations for epigenetic epidemiology. FASEB J. 2010; 24:3135-3144. [PubMed: 20385621]

90. Dogra S, Sakwinska O, Soh SE, et al. Dynamics of infant gut microbiota are influenced by delivery mode and gestational duration and are associated with subsequent adiposity. MBio. 2015; 6 pii: e02419-14.

91. Spencer SJ. Perinatal nutrition programs neuroimmune function long-term: mechanisms and implications. Front Neurosci. 2013; 12(7):144.

92. Petra AI, Panagiotidou S, Hatziagelaki E, Stewart JM, Conti P, Theoharides TC. Gut-microbiotabrain axis and its effect on neuropsychiatric disorders with suspected immune dysregulation. Clin Ther. 2015; 37:984-95. [PubMed: 26046241]

93. Piyasena C, Cartier J, Khulan B, et al. Dynamics of DNA methylation at IGF2 in preterm and term infants during the first year of life: an observational study. Lancet. 2015; 385(Suppl 1):S81. [PubMed: 26312903]

94. Teh AL, Pan H, Chen L, et al. The effect of genotype and in utero environment on interindividual variation in neonate DNA methylomes. Genome Res. 2014; 24:1064-74. [PubMed: 24709820]

95. Smit J, Cianflone K, Biron S, et al. Effects of maternal surgical weight loss in mothers on intergenerational transmission of obesity. J Clin Endocrinol Metab. 2009; 94:4275-83. [PubMed: 19820018]

96. Forbes S, Barr SM, Reynolds RM, et al. Convergence in insulin resistance between very severely obese and lean women at the end of pregnancy. Diabetologia. 2015; 58:2615-2696. [PubMed: 26248646]

97. Flegal KM, Carroll MD, Kit BK, Ogden CL. Prevalence of obesity and trends in the distribution of body mass index among US adults, 1999-2010. JAMA. 2012; 307:491-7. [PubMed: 22253363] 


\begin{tabular}{|c|c|c|c|c|c|c|c|c|c|}
\hline  & 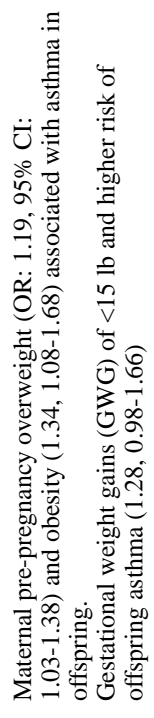 & 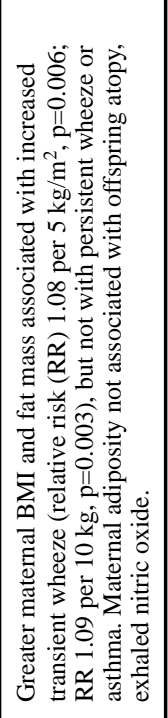 & 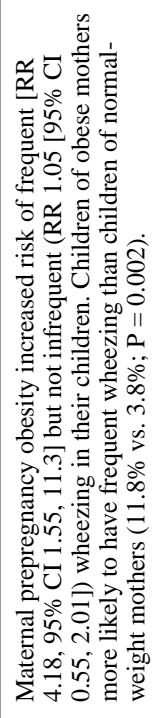 &  & 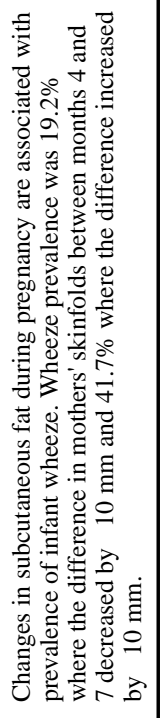 & 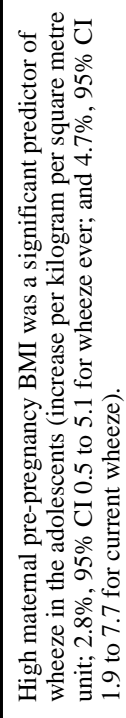 & 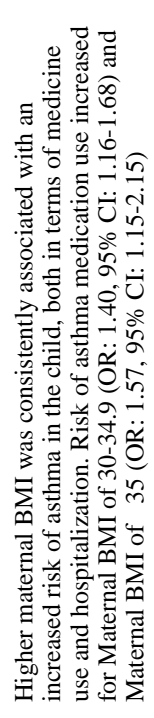 & 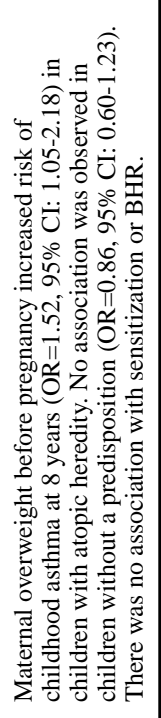 & 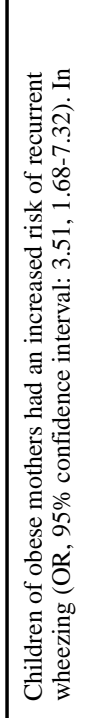 \\
\hline 鞄 & 感 & $\breve{s}$ & $\begin{array}{l}\text { 吾 } \\
\text { कू }\end{array}$ & 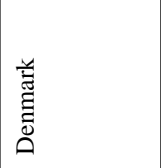 & 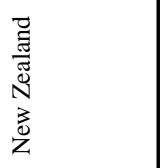 & 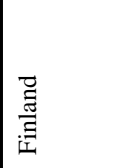 & 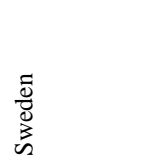 & 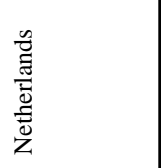 & 苑 \\
\hline 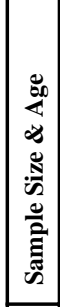 & 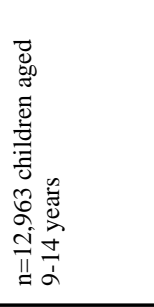 & 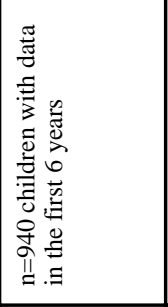 & 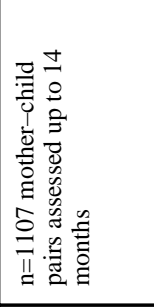 & 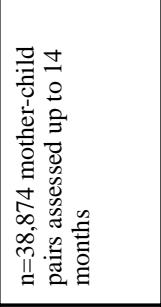 & 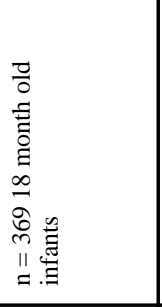 & 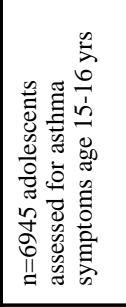 & 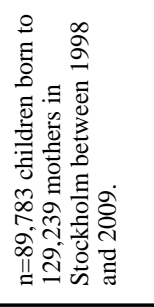 &  & 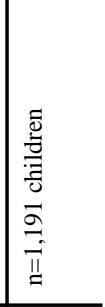 \\
\hline 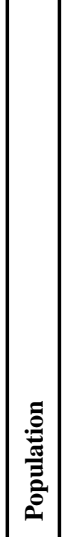 & 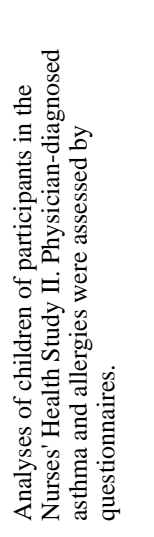 & 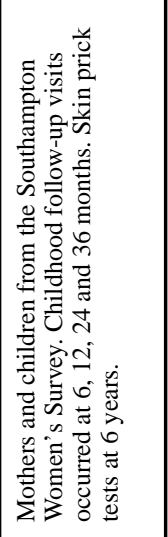 & 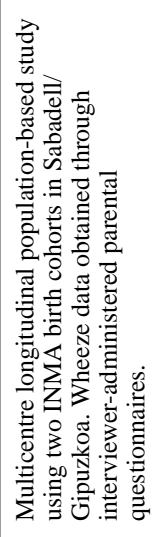 & 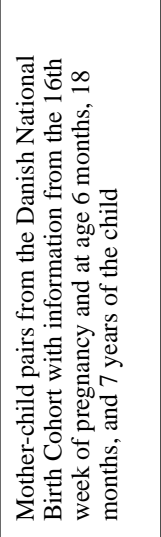 & 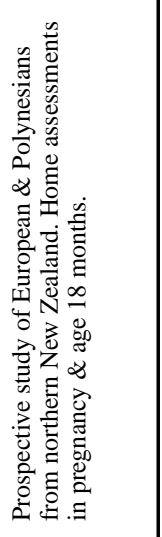 & 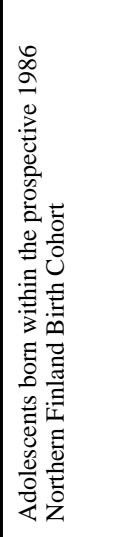 & 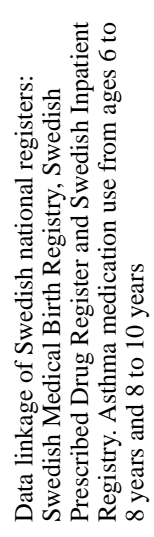 & 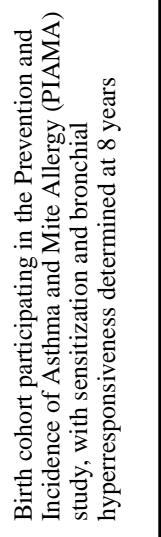 & 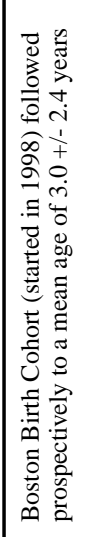 \\
\hline 离 & 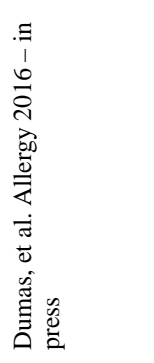 & 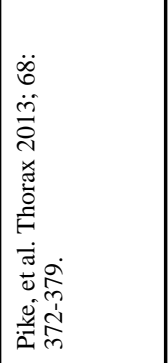 & 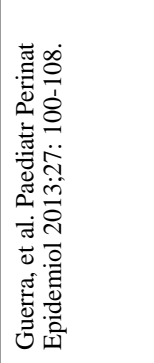 & 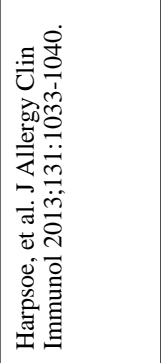 & 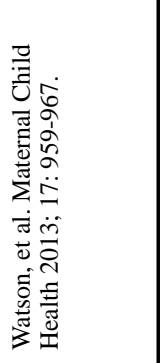 & 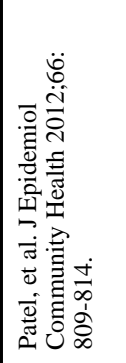 & 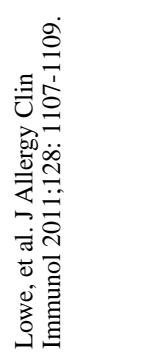 & 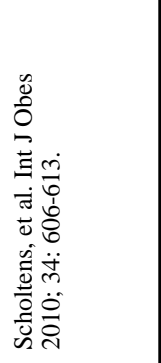 & 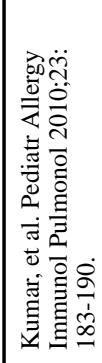 \\
\hline
\end{tabular}




\begin{tabular}{|c|c|c|c|}
\hline 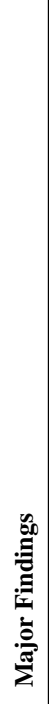 & 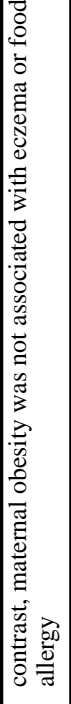 & 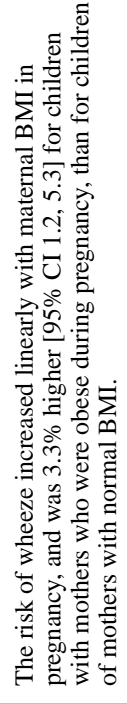 &  \\
\hline 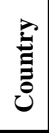 & & 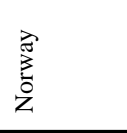 & $\begin{array}{l}\overleftarrow{b} \\
5 \\
\end{array}$ \\
\hline 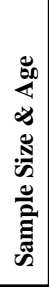 & & 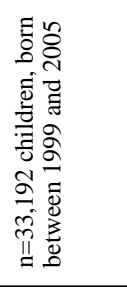 & $\begin{array}{l}\overrightarrow{2} \\
\underline{\underline{I}}\end{array}$ \\
\hline 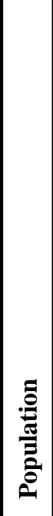 & 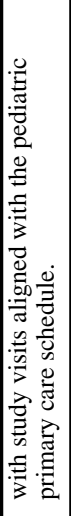 & 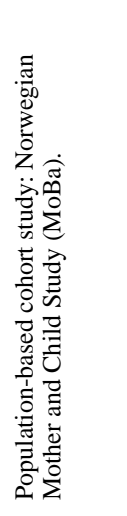 &  \\
\hline 吾 & & 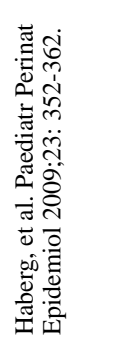 & 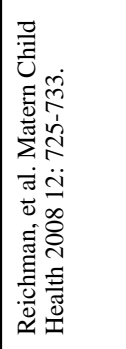 \\
\hline
\end{tabular}

Lancet Diabetes Endocrinol. Author manuscript; available in PMC 2017 July 01. 


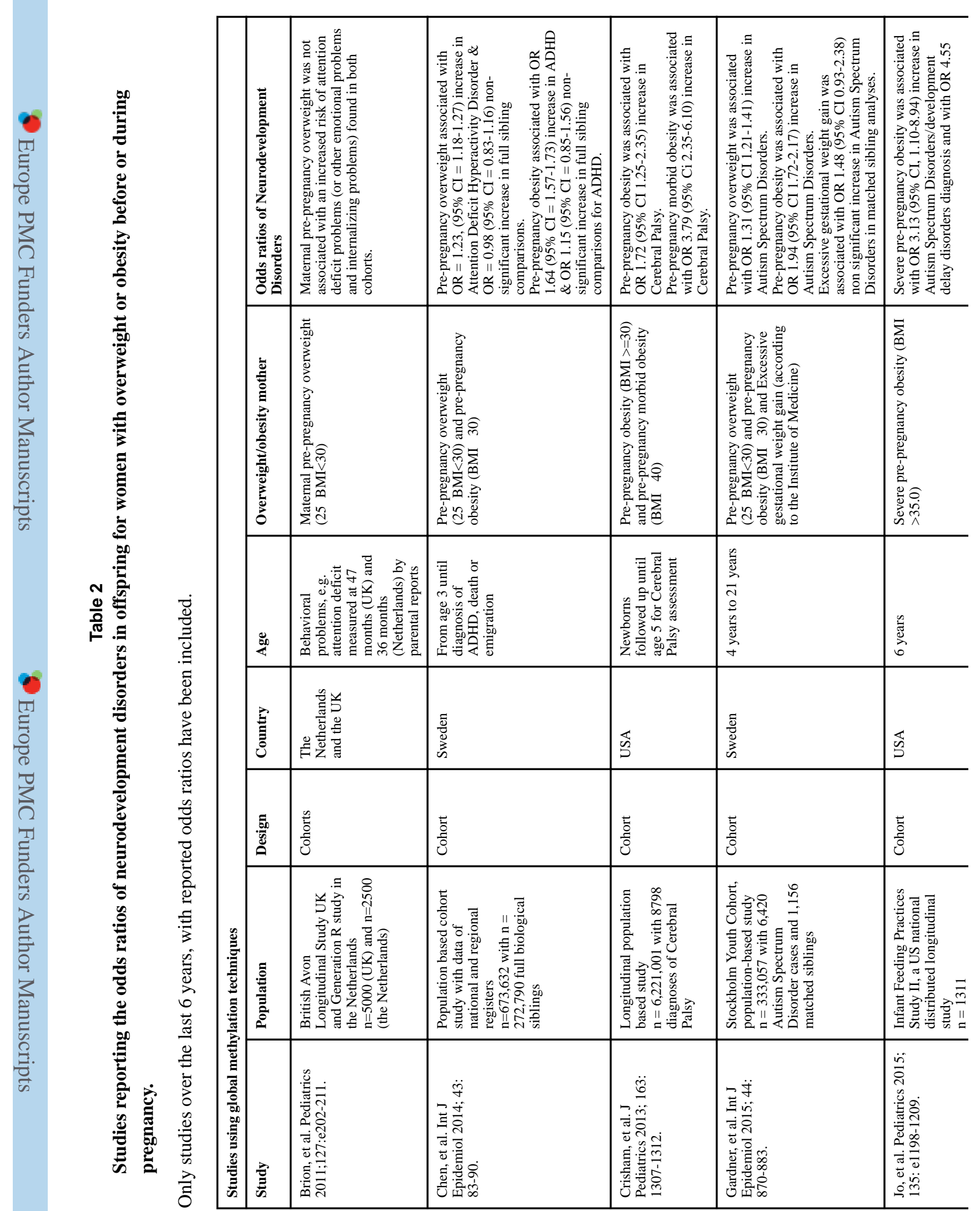

Lancet Diabetes Endocrinol. Author manuscript; available in PMC 2017 July 01. 


\begin{tabular}{|c|c|c|c|c|}
\hline 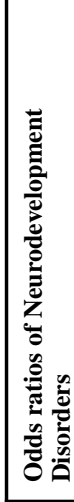 & 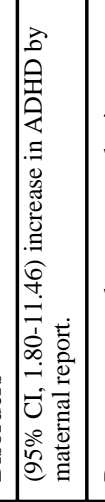 & 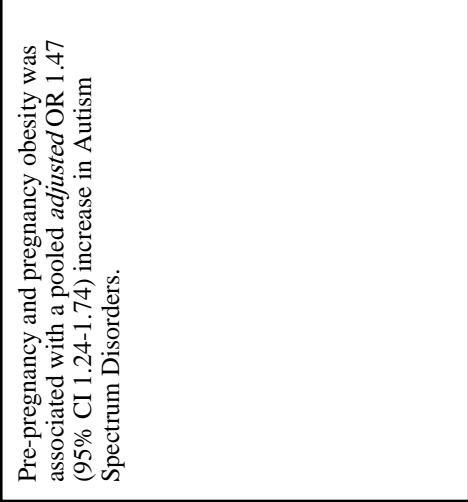 & 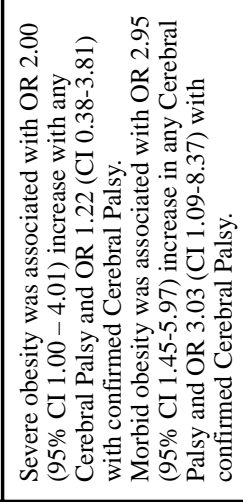 & 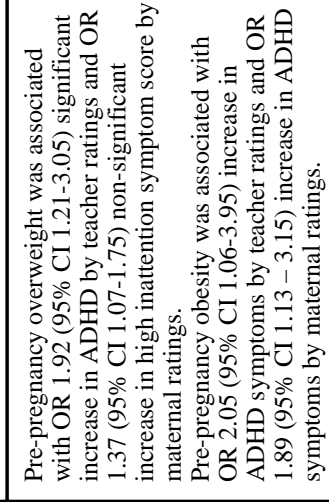 \\
\hline 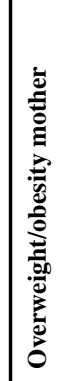 & & 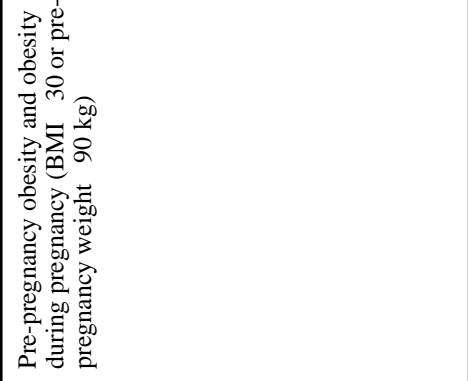 & 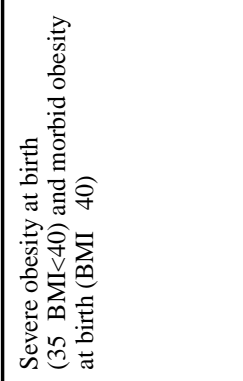 & 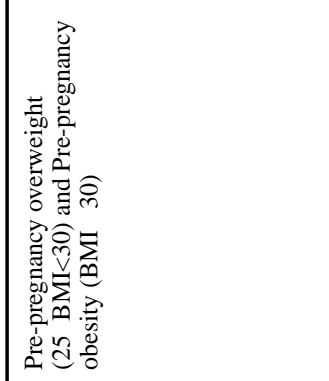 \\
\hline 哭 & &  & 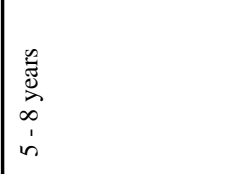 & 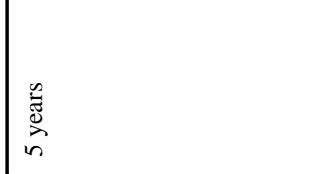 \\
\hline 害 & & 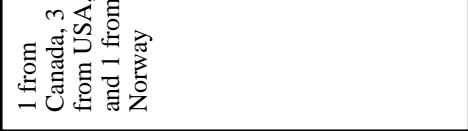 & \begin{tabular}{|l}
$x$ \\
s.
\end{tabular} & 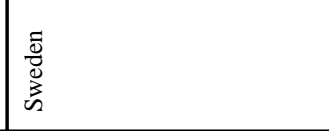 \\
\hline 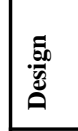 & & 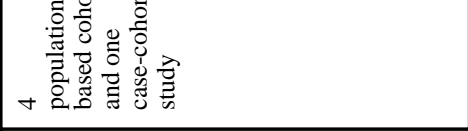 & 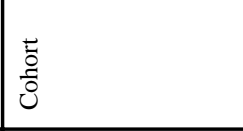 &  \\
\hline 产 & & 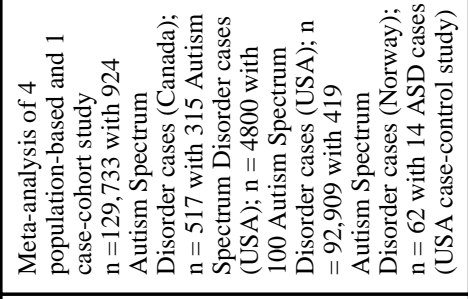 &  & 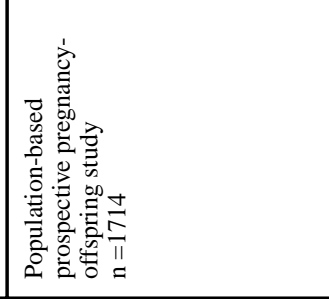 \\
\hline 童 & & 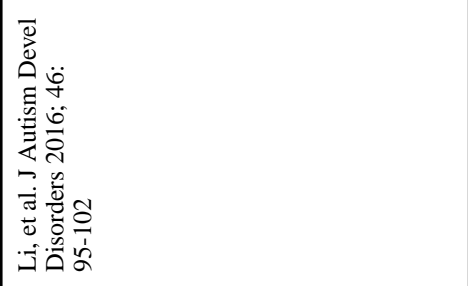 & 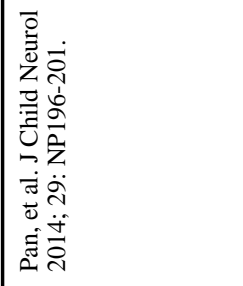 & 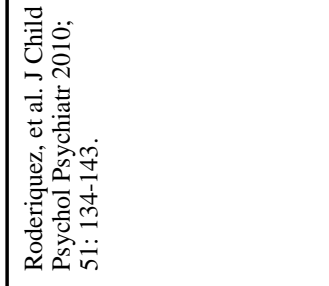 \\
\hline
\end{tabular}




\begin{tabular}{|c|c|c|c|c|c|c|c|c|c|}
\hline & 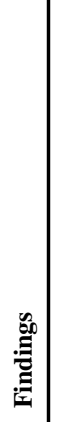 & 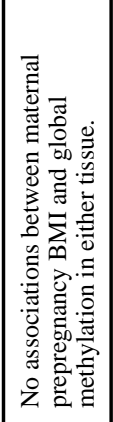 & 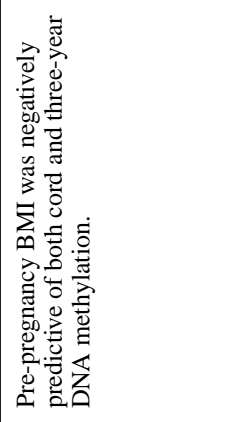 &  & 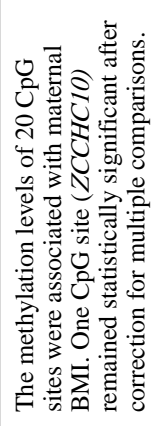 & 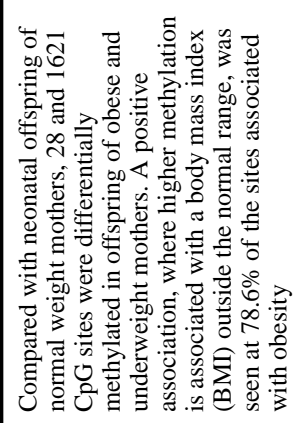 & 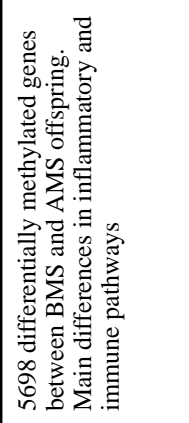 & & 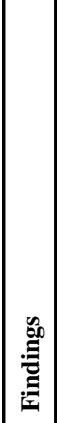 \\
\hline & 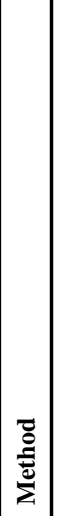 & 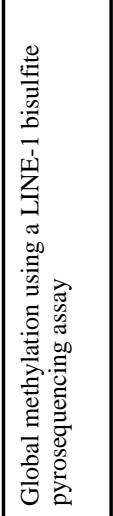 & 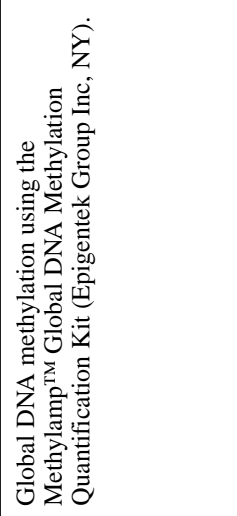 & 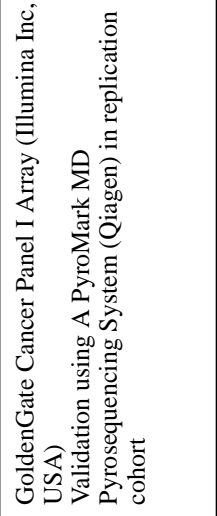 & 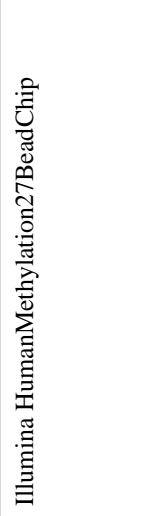 & 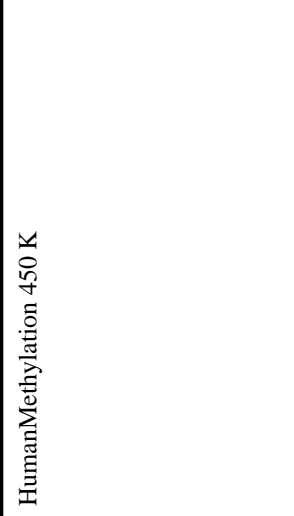 & 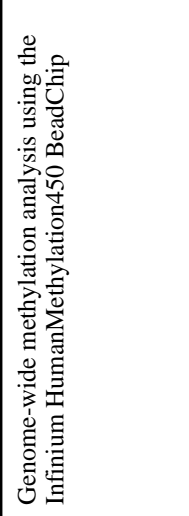 & & 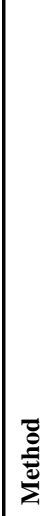 \\
\hline & 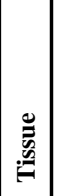 & 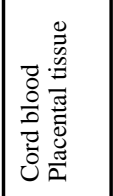 & 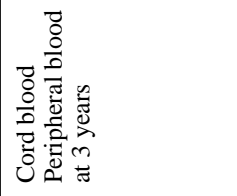 & $\begin{array}{l}\overrightarrow{0} \\
\frac{0}{0} \\
\overline{0} \\
0 \\
0\end{array}$ & $\begin{array}{l}\overrightarrow{0} \\
\frac{0}{0} \\
\overline{0} \\
0 \\
0\end{array}$ & $\begin{array}{l}\overrightarrow{0} \\
\frac{0}{0} \\
0 \\
0 \\
0 \\
0\end{array}$ & 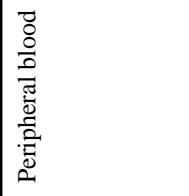 & & 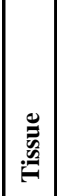 \\
\hline & 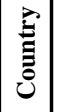 & 芯 & 勾 & $\breve{s}$ & 苑 & 光 & 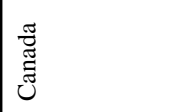 & & 音 \\
\hline & 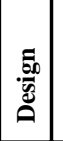 & \begin{tabular}{|l}
$\overrightarrow{0}$ \\
$\overline{0}$ \\
0
\end{tabular} & \begin{tabular}{|l}
$\overrightarrow{0}$ \\
वे \\
0
\end{tabular} & 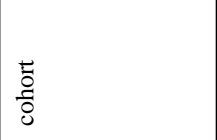 & \begin{tabular}{|l}
$\bar{t}$ \\
о \\
0
\end{tabular} & \begin{tabular}{|l} 
\\
0 \\
0 \\
0
\end{tabular} &  & & 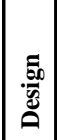 \\
\hline 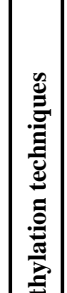 & 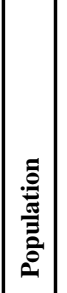 & 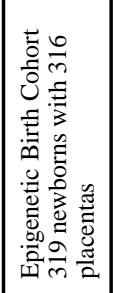 & 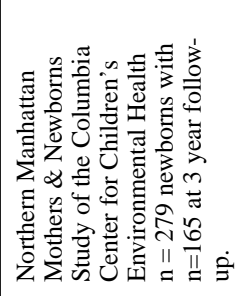 & 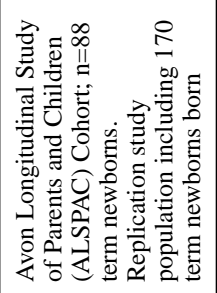 & 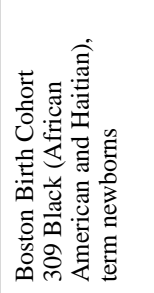 &  & 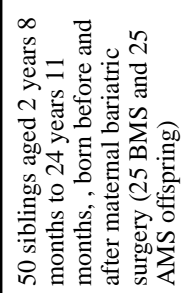 & 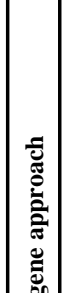 & 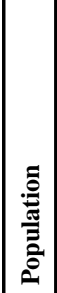 \\
\hline 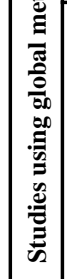 & 竧 & 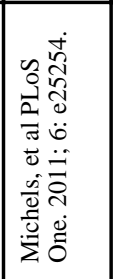 & 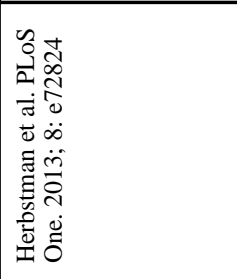 &  & 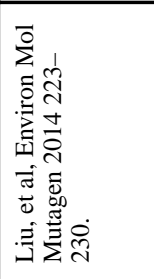 & 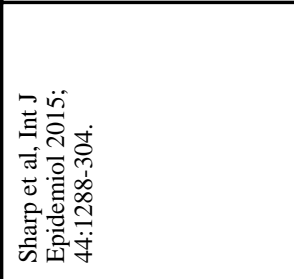 & 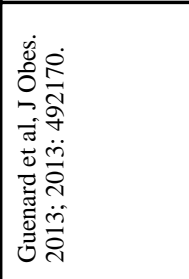 & 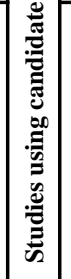 & D \\
\hline
\end{tabular}




\begin{tabular}{|c|c|c|c|c|}
\hline 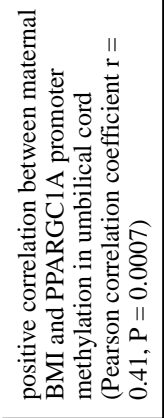 & 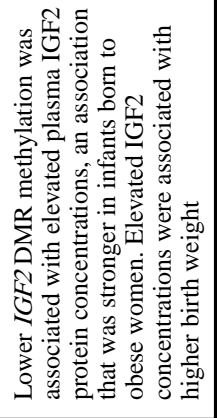 & 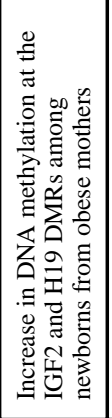 & 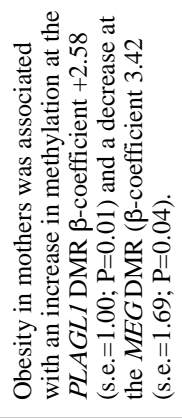 & 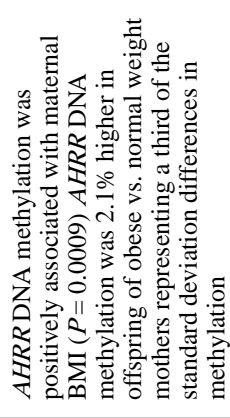 \\
\hline 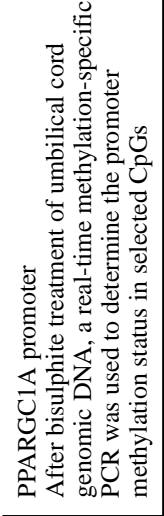 &  & 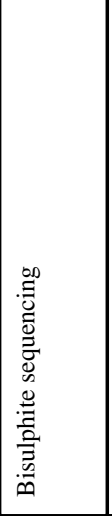 & 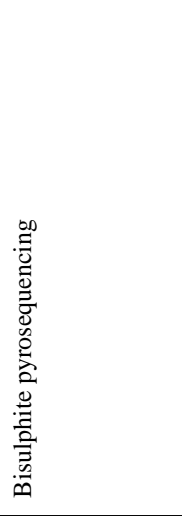 & 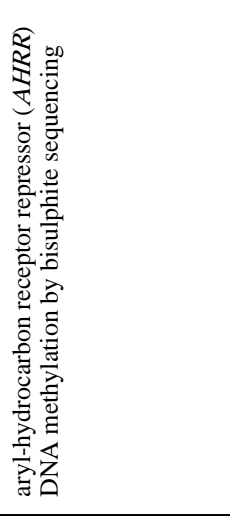 \\
\hline 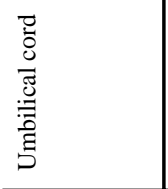 & $\begin{array}{l}\overrightarrow{0} \\
\frac{0}{0} \\
\overline{0} \\
0\end{array}$ & $\begin{array}{l}\vec{z} \\
\frac{0}{0} \\
\overline{0} \\
\dot{0}\end{array}$ & $\begin{array}{l}\overrightarrow{0} \\
\frac{0}{0} \\
\overline{0} \\
\dot{0}\end{array}$ & $\begin{array}{l}\overline{0} \\
\frac{0}{0} \\
\overline{0} \\
\dot{0}\end{array}$ \\
\hline 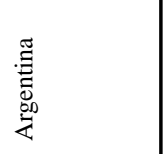 & $\begin{array}{l}\overleftrightarrow{2} \\
\tilde{\sigma}\end{array}$ & 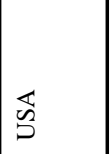 & 芯 & 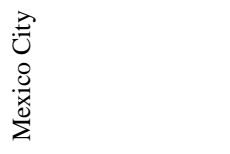 \\
\hline 营 & $\begin{array}{l}\frac{\pi}{0} \\
\frac{0}{0}\end{array}$ & 营 & $\begin{array}{l}\text { 흥 } \\
\frac{0}{0}\end{array}$ & $\begin{array}{l}\text { 밍 } \\
\frac{0}{0}\end{array}$ \\
\hline 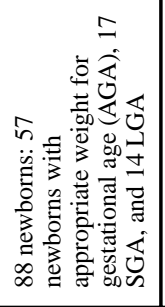 & 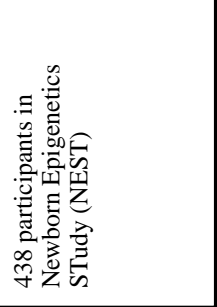 & 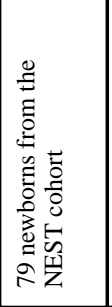 & 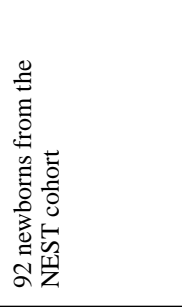 & 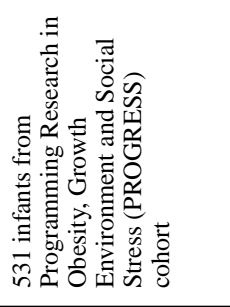 \\
\hline 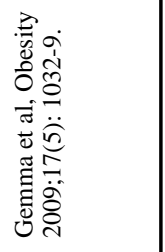 & 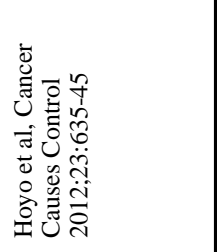 & 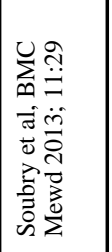 & 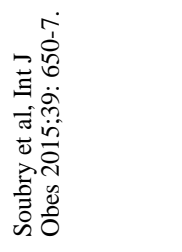 & 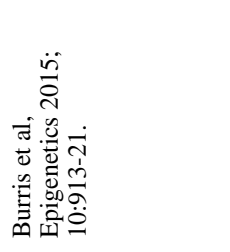 \\
\hline
\end{tabular}

Lancet Diabetes Endocrinol. Author manuscript; available in PMC 2017 July 01. 


\section{Table 4}

\section{Key points for future research}

Molecular mechanisms: Comprehensive experimental research is required into the epigenetic and other mechanisms linking maternal obesity to long term outcomes in the offspring. This will enable development of novel biomarkers and assist design of new intervention studies.

Lifestyle, nutritional and metabolic drivers: Detailed information is needed on the specific maternal lifestyle (e.g. physical activity, smoking, other environmental stressors), nutritional and metabolic exposures that underpin effects of maternal obesity on offspring outcomes. This needs to be combined with information on whether there are critical periods during development when such exposures have their effects and whether any outcomes are sex-specific.

Causality: Alongside mechanistic research, sophisticated observational studies are needed to obtain further insight into the (multiple) causalities of the observed associations. Such study designs include parent-offspring longitudinal cohorts, sib-pair analyses and the use of genetic variants and haplotypes as instrumental variables.

The need for new intervention studies: There is a paucity of intervention studies focused on remediation of maternal obesity before and during pregnancy, or on moderation of the effects of maternal obesity on the offspring. With a deeper understanding of the underlying mechanisms, new interventions need to be designed and tested, with long-term follow-up of the offspring. 